\title{
Finnish teachers' professionalism is built in teacher education and supported by school site
}

\author{
Jari Lavonen, Tiina Korhonen, \& Kalle Juuti Department of Teacher Education \\ University of Helsinki, Finland
}

\begin{abstract}
This paper introduces and analyses education of professional teachers and support of school site to this professionalism in Finnish education context. First, the aims and content of teacher education is analysed and discussed. Three main areas, crucial to the professionalism of teachers were recognised to be: teachers' knowledge base, their willingness and skill to collaboration and partnership and, moreover, willingness and skillto life-long-learning. Second, the school site support to teacher professionalism is analysed theoretically and empirically and discussed. Versatile leadership, teachers' professionalism, meaningful learning, versatile physical and virtual learning environments and, moreover, the versatile use of networks and partnerships of the school were recognised as important for teacher professionalism.
\end{abstract}

\section{Introduction}

This paper analyses education of professional teachers in Finnish education context. However, teacher professionalism is a complex concept and it has been defined in several ways. In addition several other terms, like effective, competent, expert, quality, ideal or respective teacher, are used in a similar way as a concept professional teacher (Cruickshank \& Haefele, 2001; Stronge \& Hindman, 2003). However, the concept professional teacher is different compared to the concept effective teacher. An effective teacher is recognised based on the learning outcomes of his/her students measured by a national or district level test(Goe, Bell \& Little, 2008). Simply, an effective teacher is able to support students to achieve knowledge measured in a national or district level test. An effective teacher in the U.S. context is associated with the idea of educational accountability; where testing is organized in order to recognize effective and non-effective schools and teachers (Darling-Hammond \& Youngs, 2002; Williamson \& Walberg, 2004; Muijs, 2006).

According to international research, a professional teacher is considered to have a profound and versatile knowledge base. Especially, the level and deepness of subject, pedagogical and pedagogical content knowledge are seen as the basis of professionalism (Carlsen, 1999; GessNewsome, 1999a).This knowledge base is supportive for broad planning, implementing, and assessing their own teaching and their students' learning and, moreover, improve their teaching based on these assessments (DuFour, 2004). Therefore, professional teachers are able to assess, self-regulate and -control their work. Professional ideology, incl. shared understanding of professional values and ethics code are important for professional teachers and, therefore, heavy national or district level testing or inspection are not needed. Hargreaves and Goodson (1996), Evans (2008) and Freidson (2001) emphasise in addition to knowledge base, also importance of willingness and skills needed in collaboration in networks and partnerships and, moreover, skills and willingness needed in life-long-learning. Professional teachers are able to network inside the school in grade and subject teams and, moreover, with entities outside the school, like organisations, companies around the school and with parents. As a summary, work and activities of a professional teacher is complex and not easy to standardise.

However, teacher professionalism is not only a characteristic of a teacher, but it is also a characteristic of the whole education context (Krzywacki, Lavonen, \& Juuti, 2013). Consequently, 
in addition to education of professional teachers, the support of the school site to teacher professionalism should be analysed. and discussed. The aim is of this paper is to analyse

1. education of professional teachers in Finland and

2. school site supportive for teacher professionalism. This analysis is done in the framework of relevant policy papers and literature and, moreover, based on Finnish teachers' reflections.

\section{Educating of professional teachers in Finland}

An important education policy characteristics in Finland is the culture of trust which refers to the education policymakers and education authorities at national and local level believing in teachers to know how to provide the best possible education for children and youth at a certain level (Simola, Rinne, Varjo, Pitkänen, \& Kauko, 2009). There has never been district or national level testing in Finnish comprehensive school. Moreover, there are neither national nor local school inspectors since the late 1980's. A teaching profession in Finland has always enjoyed great public respect and appreciation. The trust is seen even in the attitude of the parents to the school operations and school level quality work: Finnish parents trust school operations and teachers.

Another important Finnish education policy issue has been to raise the general standard of education and to promote educational equity (Simola, 2005). Basic decisions in this direction were made also during the 1970s along with other Nordic countries, when it was decided to change to a comprehensive obligatory school system. According to this policy all students go to common comprehensive schools and learn together as long as possible. Comprehensive school education is provided free of charge, including schoolbooks, meals, transport and health care. Although, the policymakers' vision is that Finnish students complete exactly the same nine year comprehensive school education, some minor grouping of students are made based on their abilities, for example, in mathematics and foreign languages at the school level, based on students' abilities.

The Finnish education context is challenging for teachers in ways described above. For this reason primary and secondary teachers are educated on masters-level programmes at universities. In fact, there has been a 30-year tradition of educating primary teachers (grades 1-6) and more than a 100year tradition of educating secondary teachers (grades 7-12) on masters-level programmes. Primary teachers typically teach all the subjects in a primary school, whereas secondary teachers typically teach two subjects in lower and upper secondary schools (Jakku-Sihvonen and Niemi, 2006). Primary teachers are educated at the Department of Teacher Education. Secondary teacher education is organised in a cooperation between the department of the specific discipline and the Department of Teacher Education.

According to the general national and university level strategies, teacher education should be based on scientific research and professional practices in the field. The study programme should especially provide the students with the knowledge and skills needed to operate independently as an academic professional and developer of their field. Especially, according to the Teacher Education Development Programme (2002) the teacher education programmes should help students among other things to acquire:

High quality knowledge base, like

- high-level subject knowledge, pedagogical content knowledge, contextual knowledge, knowledge about nature of knowledge, ...

- social skills, like communication skills, skills to use ICT,

- moral knowledge and skills, like moral code of the teaching profession,

Network and partnership skills, like 
- knowledge about school as an institute and its connections to the society (school community partnership; local contexts and stakeholders),

- $\quad$ skill to co-operate with other teachers, parents, ...

Life-long-learning skills, like

- skills needed in developing one's own teaching and the teaching profession,

- academic skills, like research skills,

- skills needed in processes of developing a curricula,

The secondary student teachers take a major and a minor in the subjects they intend to teach. They participate in undergraduate courses at the subject department. These courses help students develop a deep understanding of content/subject-matter knowledge and concepts as part of the conceptual framework of the subject. Teachers need this knowledge when they guide students in problem-solving activities or when they ask high quality questions and, moreover, when they organise formative and summative assessment activities (Lavonen, Krzywacki-Vainio, Aksela, Krokfors, Oikkonen \& Saarikko, 2007). The students study also pedagogical content knowledge within their masters level courses at some departments, like the Departments of Physics and Chemistry. They especially become familiar with how to introduce a certain concept through a demonstration or through lab activities. Moreover, they learn how a certain concept is related to other concepts, natural laws and theories in a certain domain of knowledge during a course focusing on the meanings of concepts. Furthermore, they learn the historical and philosophical bases of the subjects they teach. Several activities within the courses support students in planning instruction. These three courses support the development of PCK (Lavonen, Jauhiainen, Koponen, \& Kurki-Suonio, 2004). Moreover, PCK is learned during the pedagogical studies as described below.

A core topic in both primary and secondary teacher education is pedagogical studies. According to the curriculum of pedagogical studies, the students should become aware of the different dimensions of the teaching profession, like the social, philosophical, psychological, sociological, multicultural, and historical bases of education, and obtain a readiness for different kinds of partnerships, like school - home and school - society partnerships. The pedagogical studies supports the students to combine educational theories their subject knowledge as well as their personal histories (cf. Trotman and Kerr, 2001). During their pedagogical studies, the students are supported in integrating subject matter and pedagogical content knowledge; educational theories, like theories of learning, motivation and self-efficacy; their own experiences of teaching and learning and, moreover, their experiences of school practices into their students' own personal pedagogical theories or views. The students learn to collaborate in different networks and partnerships and obtain a readiness, for example, for co-operation in a multiprofessional team where social workers, school psychologists and special education teachers collaborate and look after the well-being of school students. Because, the student abilities are relatively heterogeneous in comprehensive schools, much emphasis is given to different types of learners, the versatile planning of the teaching, teaching and learning methods and to the teachers' roles, through formal and informal assessment and feedback and encouraging the students. The courses within pedagogiocal can be classified into four categories: general courses in education, educational research, subject pedagogy courses and teaching practice. (Kansanen, Tirri, Meri, Krokfors, Husu \& Jyrhämä, 2000; Lavonen, Krzywacki-Vainio, Aksela, Krokfors, Oikkonen \& Saarikko, 2007)

An essential characteristic of primary and secondary teacher education in Finland is an emphasis on research orientation (Jakku-Sihvonen \& Niemi, 2006). From the point of view of this orientation, the student teachers learn how to consume and produce educational knowledge within their pedagogical studies (Gitlin, Barlow, Burbank, Kauchak \& Stevens, 1999; Pendry and 
Husbands, 2000; Reis-Jorge, 2005). A student consumes educational-research-based knowledge when he or she combines theory and experience or interprets a situation during his/her teaching practice. The capacity to produce educational knowledge is learned by students during their research methodology courses and while conducting their educational research projects (Bachelor, Pedagogical and Masters dissertations) (Gore and Gitlin, 2004). Therefore, the research orientation within the pedagogical studies help them to develop potentials for lifelong professional development.

Teaching practice is altogether one third of the pedagogical studies. During the teaching practice, the students are supported to transform practitioner (practical) knowledge into professional knowledge through reflective activities and guided discussions in small groups. Reflection refers here to a process in which an experience is recalled, considered, and evaluated, in relation to learning from practice (Zimmerman, 2002). Mentor teachers who supervise teaching practice at the teacher training school support student teachers in a meaning-making process through facilitating the setting of aims for teaching practice; making observations of one's own behaviour in practice; the describing of observations and experiences, and analysis of observations and experiences (Rodgers, 2002). The role of trained supervision during the practice is central, and a trained mentor teacher helps the student to include all the possible aspects of a teacher's work in their reflection. During the advanced-practice stage, the student teacher becomes increasingly independent, and the discussions with supervisors are expected to become deep and detailed. They learn to reflect for (reflection during the planning phase), in (reflection during the teaching) and on (reflection after the lesson) action.

\section{The school site supportive for teacher professionalism}

The school site supportive for teacher professionalismemphasises four characteristics of a school: students' learning and learning environments, teachers' professionalism, leadership and, moreover, partnerships and networks of the school.

\section{Students' learning and learning environments}

The Finnish national and school level curriculum emphasise meaningful learning (Bransford \& Donovan, 2005) and the learning of 21st century competences in versatile learning environments (Vahtivuori-Hänninen, Halinen, Niemi, Lavonen, Lipponen \& Multisilta, 2014). Especially, students should learn to think critically and creatively, use of a wide range of tools in creativity and interaction, engage and interact in heterogeneous groups as well as act autonomously and take responsibility of managing their own lives. Due to the students' diverse backgrounds, it is important to utilize a variety of teaching methods to engage students in 21 st century competences. A learning environment refers to the diverse physical locations, contexts and cultures in which students learn (Fraser, 1994). A learning environment does not need to be a physical place, it can also be virtual, online, or remote. Goal orientation and interaction are supported through the ICT tools available in the learning environment, including basic writing and drawing applications, social media environments as well as various types of mobile devices and other tools that facilitate flexible, remote and mobile learning. High-quality learning materials, including digital learning materials such as learning games and other interactive learning content are essential parts of the learning environment.

\section{Teachers' professionalism}


Professional teachers are at the heart of the Finnish school. A professional teacher is seen as an academic professional who is committed to his/her work and is able to plan, implement, and assess his/her own teaching and his/her students' learning. He/she formatively monitors the progress of students, particularly those with special needs, and try to support all students' learning (DuFour, 2004; Niemi, Toom \& Kallioniemi, 2012).

The previous chapter describes already the professionalism a student should learn within the masters level teacher education programs. This professionalism is close to competences described in "teacher leadership" thinking (Katzenmeyer \& Moller, 2001, 17). Lieberman (1992) and Harris (2003) have outlined this type of teacher. He or she is goal oriented and has a clear vision for school development and, moreover, is able to plan, implement and assess his/her own practice and students' learning, has deep understanding on teaching and learning and is able to work collaboratively and in interaction with other teachers towards the goals. He or she is considered to be able to consume research based knowledge and has deep understanding on teaching and learning in order to act as a curriculum specialist and is able to use assessment outcomes for school development.

\section{Leadership}

The professional culture in a school plays a major role in supporting teachers' collaboration and classroom operations such as teaching and assessment (Chong, Huan, Wong, Klassen \&Allison, 2010). The role of the school principals and their leadership approaches, such as the sharing of responsibilities, or shared leadership, influence teachers' collaboration and classroom operations. Teachers are positively influenced when school leaders encourage collaboration among teachers, students, families, and other school personnel. (Caprara, Barbaranelli, Borgogni \& Steca, 2003; Caprara, Barbaranelli, Steca \& Malone, 2006). Therefore, school principals in the ISM have an important role in facilitating a school culture that supports teachers' collaboration. In practice, this collaboration manifests itself in various school teams and networks, such as grade level teams and multi-professional teams.

\section{Partnerships and networks}

Parents are most important partners in education. A fruitful partnership with parents facilitates the sharing of responsibility for students' weekly activities. In practice, family events and personal meetings with teachers are important to organize. ICT offers a multitude of opportunities for enhancing home and school collaboration (HSC), and could be applied to enable continuous interaction between the school and families (Korhonen \& Lavonen 2014). The aim of HSC is for parents and teachers to share educational values and goals, with the important consequence that mutual trust is established in each other's ability to work towards supporting the child's growth and education. In addition to HSC a wider view of partnerships with the local community such as school support personnel, day-care providers, public librarians and senior homes as well as actors in national and international networks is important. An essential part of all partnership is respect for the thoughts, opinions and wishes of all stakeholders. Through long-term collaborative development, more families, teachers and community members learn to work with each other as parts of a community for the benefit of the children (Epstein 2009).

\section{The outcomes of interviews of professional teachers}

Rodgers (2002) emphasises, referring to Dewey's work, "that the process of reflection is rigorous and systematic and distinct from other, less structured kinds of thinking" (Rodgers, 2002, p. 863). 
Common reflection is understood here as data gathering method. The authors of the paper and three teachers of one school reflected together aiming to recognize how a school site supports teachers' professionalism in January 2014.Therefore, during the reflection it was focused on the properties of the environment, like leadership, teacher professionalism, networks and partnerships and, moreover, physical and virtual learning environments of the school,

The written reflections (transcriptions)were analysed following the ideas of inductive content analysis (Elo \& Kyngäs, 2008). The reflections were read several times in order to ensure an accurate interpretation of the expressions. Moreover, the interpretations were read and discussed in order to get a mutual understanding of the interpretations.

The teachers see their school building rather traditional including standard classrooms and, moreover, a couple of special classrooms like a workshop for handicraft teaching, a minor science and technology lab and a music class. The teachers feel that the structure of physical environments does not enough support the versatile grouping of students. However, the teachers and students have used their creativity and created learning spaces all over the school building. They have, for example, used curtains and pillows for creating these spaces to the corridors and other areas of the school: "Large pillows are easy to move and offers flexibility for creation of learning spaces" (Teacher 3); "It is important there are versatile learning spaces where students are able to engage in learning alone or in a small group" (Teacher 2). Moreover, the students learn in out-of-school locations such as a library and outdoor environments such as parks where mobile ICT tools are used for learning.

In their reflections the teachers analysed spontaneously the physical and virtual environments supportive for the learning. The development of the environments is based on strategic planning: "It is important the teachers share a common goal on the use of ICT in teaching and learning and support each other to approach these goals"(Teacher 2); "More we have ICT tools and resources, more we need co-planning, organising and support" (Teacher 1). The teachers agreed that there are enough basic ICT tools, like computers and data projectors at the school. However, the Internet connection and wireless network is undeveloped. The city is not able to offer these services: "The capacity of wireless network is limited for the large use of mobile devices" (Teacher 3). Furthermore, the city is not able to offer enough technical support to the teachers. Moreover, the web-based learning environments do not support the use of mobile devices and, therefore, different cloud services, like Sky One Drive, are used. From the point of view of personalisation of learning there are not enough basic laptops or mobile devices: "From the point of view of personalisation each student need own laptop" (Teacher 3).

The teachers described students learning in the learning environments of the school in the context of meaningful learning. They, for example, emphasized student activity (Students plan their own activities to the breaks and borrows tools or equipment for these activities, Teacher 2), construction of knowledge (Our students are looking for information from different sources, Teacher 1), collaboration and interaction (Students at the same grade level are collaborating and they can select the space in or out-of-school for learning and collaboration, Teacher 3) and reflection and selfevaluation (When students are able to choose their learning space, their reflection and selfregulation skills will improve, Teacher 3 ).

In their reflections, the teachers analysed teachers and classroom assistants knowledge to be supportive for planning, organising and evaluating learning and learning outcomes: "Teachers have high level competence and this competence they use in teaching and supervision of students" (Teacher 1); "Teachers are able to take into account diverse need of students" (Teacher 2); "In our 
school teachers has versatile subject and pedagogical knowledge" (Teacher 3). Teachers are skilled to use versatile learning environments and ICT tools. Teachers of the school are skilled in networking as introduced in previous and last sub-chapter.

Teachers were eager to learn, adopt educational innovations, from each other and have a strong orientation to life-long-learning. This is supported through weekly meetings: "We share experiences and know-how in pedagogical coffee meetings" (Teacher 1); "Teachers are eager to develop their own work and interested about new innovations" (Teacher 2); "Everybody is willing to learn more knowledge and skills" (Teacher 3). Teachers are especially eager to learn new technology and use of this technology in education: "It is important to learn to use new technology continuously" (Teacher 3); "It is challenging for teachers to learn to use new technology continuously" (Teacher 2).

All three teachers emphasized in their reflections the importance of strategic planning and goal orientation ("You can recognize goal orientation in the operations of the school" (Teacher 2), interaction ("All topics are discussed with teachers" (Teacher 2); "Interaction is organized through monthly meetings and weekly info breaks" (Teacher 3)and openness of the processes ("Openness and informing of forthcoming issues is important" "It is important to plan together all operations, like break activities and celebrations." (Teacher 1). There should be versatile interaction forums in leadership in a school, operating in the context of ISM. Teachers of the school meet once a month in official teacher meetings and once a week in informal "noon"-meetings. Moreover, there are, for example, team meetings of the teachers working at the same grade. Furthermore the official development discussions and unofficial daily personal discussions are important for teachers. Because of the versatile use of ICT in leadership, the interaction situations are both face-to and virtual type. These three basic characteristics of leadership support teachers in planning and implementing their teaching and assessment and, moreover, planning of educational innovations.

Important in leadership is shared/distributed leadership or team leading and awareness of the duties (division of labour) of main and vice principals: "The strength in leadership is shared leadership" (Teacher 1). The idea of team working is distributed to teacher level. Teachers and classroom assistants at a grade level belong to a team. This "grade-team" is responsible for co-planning and evaluation: "A grade-team has common tasks and aims" (Teacher 3). ICT is used in a versatile way in administration. The principals, teachers and classroom assistants work together to develop ways to use ICT in administration and collaboration: "ICT is used in school-home collaboration" Teacher 1. The use of ICT in school operations support the teachers to acquire ICT skills the teachers can utilize in their teaching as well. It is important that the school follows technology developments on the principal, teacher and classroom level.

The role of a principal is important in designing educational innovations and in supporting the teachers to adopt innovations: "It is important to understand that the educational innovations, like co-teaching in a very heterogeneous group, programming of robots in order to support the development of students creative and critical thinking, developed by one group of teachers are not typically adopted by other teachers during the year when the innovation is designed. The experiences, collected during the design phases, and the model of the innovation should be introduced to the other teachers and they should be supported in the adoption process. The teachers and the principals should share a common vision how teachers are supported in the adoption process, how versatile discussion and collaboration supporting the adoption is organised. The role of the school principal is important." (Teacher 2). This describes also challenges in leadership, like supporting different teachers and starting where they are. Because of the integration of all kind of 
learners in the same classroom teachers meet challenges and need support of the principal ("I need more pedagogical support from the principal side in the case of challenging students" (Teacher 3 ).

Teachers recognised the networks and partnership in five levels in their reflections. In all levels ICT is used: "The use of ICT, supporting networking, has been developed for a long time." (Teacher 1). Inside the school there are several networks, like grade-level networks or teams and school-level networks, like multiprofessional team: "Multiprofessional team (school nurse, social worker, special need teacher and principal) supports the welfare of students" (Teacher 3). At city level the teachers of the school belongs to several networks, like local curriculum development team and inservice training team: "I am active in special need education network and in consulting teacher network" (Teacher 2). Networks with families and institutes are more partnership-type than network-type and discussed in a chapter below. The school is networking with several other schools in Finland and aiming to develop, for example, the use of ICT in education and collaboration, in those teams: "We belong to broad network of schools and aim to develop the use of technology in education through these networks" (Teacher 3 ).

The school is in partnership type collaboration with several organisations, like library, kindergarten and senior house, around the school. This collaboration allows the students possibilities to learn and collaborate in those organisations. On the other hand these organisations get benefit from these partnerships. The students, for example, visit the sites and organise activities for the people at the site. The students have, for example, introduced the use of mobile devices to old people at senior house or kids at the kindergarten. All teachers emphasised that collaboration with parents is an important type of networking for the school: "School-family collaboration is organised through parents' club and classroom committee activities. The parents are very interested to make an impact to school operations. The parents' club organises different kind of activities for students, parents and teachers during the evenings or weekends" (Teacher 1); "Networking with families is partnership and a resource for our school" (Teacher 3).

The teachers emphasised that most challenging in future is to continue the partnerships and networks with all important parties. Especially, the updates to the ICT tools require continuous learning: "Several parents blame the usability of the new version of the software, used in schoolhome collaboration" (Teacher 1). Another challenge in the use of ICT is the variation in the competence of the parties. Especially, the variance among parents' ICT competence and ICT tools available makes the networking challenging: "All families are not able to benefit of the school-home collaboration, because of the lack of competence, tools and lack of common language" (Teacher 3). The third challenge is the resources needed in coordinating the networks. One teacher feels that the school has too many networks: "In my opinion, there are too many networks and we do not utilise them enough" (Teacher 2). Especially, networking with some companies is not fruitful: only the companies benefit from the collaboration.

\section{Discussion}

We have analysed education of professional teachers and operations and support of a school to this professionalism in the Finnish education context. Three main areas, crucial to the professionalism of teachers were recognised to be: teachers' knowledge base, their willingness to collaboration and partnership and, moreover, to life-long-learning. Development of these knowledge and skills are supported through teacher education. For example, research orientation and reflective activities are supportive for the development of life-long-learning competences. Teachers' knowledge and skills are supportive for broad planning, organising and evaluating learning and learning outcomes. Networking is important and productive inside the school in multiprofessional teams and with 
entities outside the school, like organisations and companies around the school and, moreover, with parents. This professionalism of teachers is supported through collaboration, common projects, networks and leadership at school level (Hargreaves \& Goodson, 1996; Evans, 2008). Testing, inspection and control or accountability are not recognised in Finnish schools (Williamson \& Walberg, 2004; Muijs, 2006)

Our analysis of the school operations focused to leadership, teacher professionalism, learning environments and networks. The goal- or strategic orientation, versatile collaboration models, like the grade-teams, and leadership support the school operations and teachers in planning, implementing and adopting of educational innovations (Mangin, 2007; Scribner \& Bradley-Levine, 2010; Chong, Huan, Wong, Klassen \& Allison, 2010). Forums for interaction are needed in three levels: school level interaction through official teacher meetings and informal "noon" meetings; team meetings of the teachers; and the official development discussions and unofficial daily persona discussions. These types of interactions could happen in face to face situations or through school web page, intranet and emails. Moreover, clear structure and division of work and duties among the principal and vice-principal are important characteristics of shared leadership. Finally the openness of the processes supports the teachers' participation to the common operations of the school.

Strategic planning is needed in the development of physical and virtual environments for better supporting the learning of 21st century competences (Binkley, Erstad, Herman, Raizen, Ripley, Miller-Ricci, \& Rumble, 2012). In the planning of environments, the use of versatile ICT facilities should be taken into account. For example mobile devices are used all over the school and smart boards are needed not only in the classrooms. Learning environments support networking and meaningful learning which is grounded on activity and intention, reflection and self-evaluation, collaboration and interaction, construction, contextualization, and cumulative learning (Bransford \& Donovan, 2005). Consequently, students learn in a wide variety of settings and groupings, including out-of-school locations such as a library as well as outdoor environments such as parks, making use of mobile ICT tools (Fraser, 1994).

Acknowledgments

This chapter was made possible with support from the Finnable 2020 project, funded by the Finnish Funding Agency for Technology and Innovation (Tekes).

\section{References}

Bennett, J., Lubben, F., Hogarth, S. \& Campbell, B. (2004). A systematic review of the use of smallgroup discussions in science teaching with students aged $11-18$, and their effects on students' understanding in science or attitude to science. In Research Evidence in Education Library. London: EPPI-Centre, Social Science Research Unit, Institute of Education.

Binkley, M., Erstad, O., Herman, J., Raizen, S., Ripley, M., Miller-Ricci, M. \& Rumble, M. (2012). Defining twenty-first century skills. In P. Griffin, B. McGaw \& E. Care (Eds.) Assessment and teaching of 21st century skills (pp. 17-66). Dordrecht: Springer.

Bransford, J. D., \& Donovan, S. M. (2005). How students learn science in the classroom. Washington, DC: National Academies Press. 
Caprara, G.V., Barbaranelli, C., Steca, P., \& Malone, P. S. (2006) Teachers'self-efficacy beliefs as determinants job satisfaction and students' academic achievement: A study at the school level. Journal of School Psychology, 44, 473-490.

Chong, W. H., Huan, V. S., Wong, I., Klassen, R. M., \& Allison, D. K. (2010). The relationships among school types, teacher efficacy beliefs, and academic climate: Perspective from Asian middle schools. The Journal of Educational Research, 103, 183-190.

Darling-Hammond, L. (2009). Steady Work: How Finland Is Building a Strong Teaching and Learning System .V.U.E. Summer 2009

Darling-Hammond, L., \& Youngs, P. (2002). Defining "highly qualified teachers": What does "scientifically-based research" tell us? Educational Researcher, 31(9), 13-25.

DuFour, R. (2004). What is a "professional learning community"? Educational Leadership, 61, 611.

Elo, S. \& Kyngäs, H. (2008). The qualitative content analysis process. Journal of Advanced Nursing, 62(1), 107-115.

Epstein, J.L. (2011). School, family, and community partnerships, Second Edition. Westview Press. Fraser, B.J. (1994). Classroom and school climate. In Gabel, D. (Ed.), Handbook of Research on Science Teaching and Learning (pp. 493-541). Macmillan, New York.

Fullan, M.(2007).The New Meaning of Educational Change. 4rd ed. New York and London: Teachers College Press.

Hargreaves, A., \& Goodson, I. (1996) teachers' professional lives: aspirations and actualities. In I. Goodson and A. Hargreaves (eds) Teachers' Professional Lives. London: Falmer.

Evans, L. (2008). Professionalism, professionality and the development of education professionals. British Journal of Educational Studies, 56 (1), 20-38.

Harris, A. (2003). Teacher Leadership as Distributed Leadership: heresy, fantasy or possibility? School Leadership \& Management, 23(3), 313-324.

Katzenmeyer, M. \& Moller, G. (2001). Awakening the Sleeping Giant: Helping Teachers Develop as Leaders. Thousand Oaks, CA: Corwin Press.

Korhonen, T. \& Lavonen, J. (2014). Crossing school-family boundaries through the use of technology. . In H. Niemi, J. Multisilta \& E. Löfström (Eds.) Crossing Boundaries for Learning through Technology and Human Efforts (pp. 48-66). Helsinki: CICERO Learning Network, University of Helsinki.

Kukkonen, M. \& Lavonen, J. (2014). Crossing Classroom Boundaries through the Use of Collaboration-Supporting ICT: A Case Study on School -Kindergarten - Library - Senior Home Partnership. In H. Niemi, J. Multisilta \& E. Löfström (Eds.) Crossing Boundaries for Learning - 
through Technology and Human Efforts (pp. 67-90). Helsinki: CICERO Learning Network, University of Helsinki.

Lieberman, A. (1992). Teacher leadership: What are we learning? In C. Livingston (Ed.), Teachers as leaders: Evolving roles. NEA School Restructuring Series. Washington, DC: National Education Association.

Mangin, M.M. (2007). Facilitating Elementary Principals' Support for Instructional Teacher Leadership. Educational Administration Quarterly, 43(3), 319-357.

Muijs, D. (2006). Measuring teacher effectiveness: Some methodological reflections. Educational Research \& Evaluation, 12(1), 53-74

Niemi, H. Toom, A., \& Kallioniemi, A. (2012). Miracle of Education: The principles and practices of teaching and learning in Finnish schools. Rotterdam: Sense Publishers.

Rogers, E. M. (2003). Diffusion of innovations (5th ed.). New York: Free Press.

Scribner, S.M.P. \& Bradley-Levine, J. (2010). The Meaning(s) of Teacher Leadership in an Urban High School Reform. Education Administration Quarterly, 46(4) 491-522

Sormunen, K., Lavonen, J. \& Juuti, K. (2014). Crossing Classroom Boundaries in Science Teaching and Learning through the Use of Smartphones. In H. Niemi, J. Multisilta \& E. Löfström (Eds.) Crossing Boundaries for Learning - through Technology and Human Efforts (pp. 91-111). Helsinki: CICERO Learning Network, University of Helsinki.

Vahtivuori-Hänninen, S. H., Halinen, I., Niemi, H., Lavonen, J. M. J., Lipponen, L., \& Multisilta, J. (2014). A new Finnish national core curriculum for basic education (2014) and technology as an integrated tool for learning. In Niemi, H., Multisilta, J., Lipponen, L. \& Vivitsou, M. (Eds.),Finnish Innovations \& Technologies in Schools: a Guide towards New Ecosystems of Learning (pp. 33-44). Sense Publishers.

Williamson M.E., \& Walberg H.J. (Eds.) (2004). Testing Student Learning, Evaluating Teaching Effectiveness. Stanford: Hoover Institution Press: Stanford University. 